\title{
Construção de um Modelo para Análise da Formação Profissional do Psicólogo
}

Este artigo descreve o processo de desenvolvimento de um instrumento de análise voltado para estudo do fenômeno "Formação Profissional", objeto de um pesquisa conduzida pelas autoras. Tal modelo possibilitou a classificação e comparação de informações relacionadas à formação do psicólogo encontradas em artigos publicados em periódicos nacionais e cumpriu sua função quanto à previsão de aspectos do fenômeno em questão.

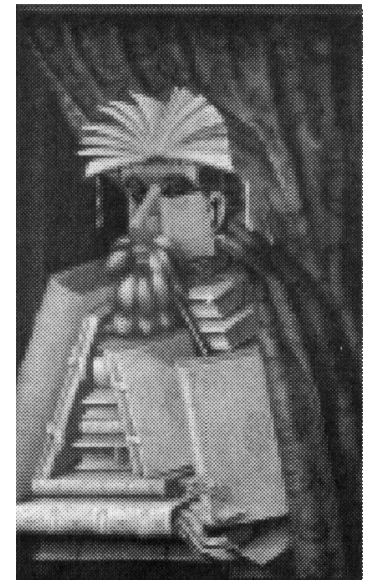

Maria Benedita Lima Pardo, Regina Helena Corsi Mangieri \& Mara Silvia Aparecida Nucci Departamento de Psicologia Universidade Federal de São Carlos.

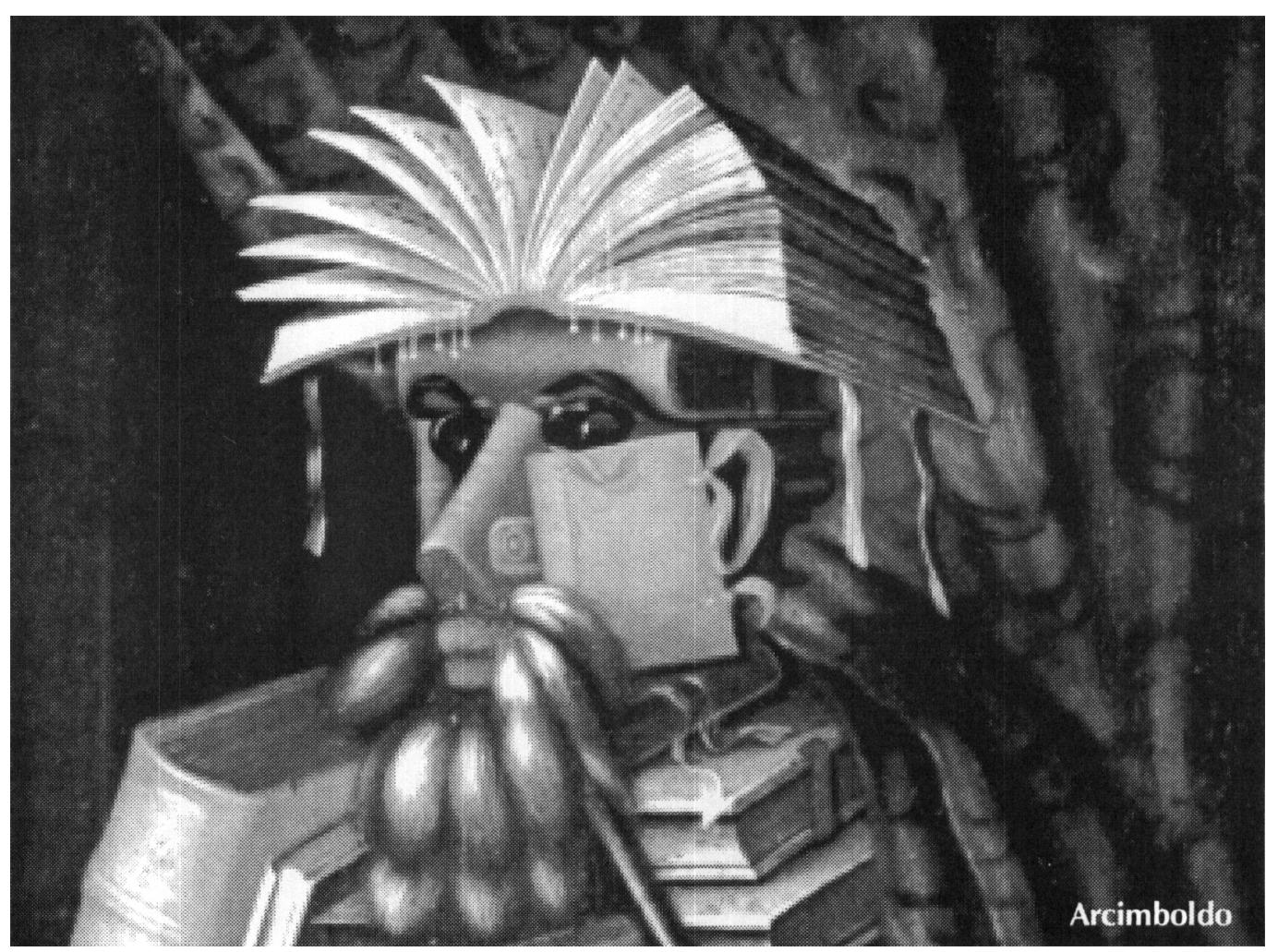

Ao realizar seu trabalho, o pesquisador percorre uma série de etapas que se iniciam com a definição do problema de pesquisa e continuam com a definição dos objetivos, levantamento de hipóteses e pesquisa a literatura. A seqüência cronológica de realização das etapas não pode ser delimitada rigidamente pois o trabalho sobre cada uma delas ajuda a definir características que as outras deverão assumir. Por exemplo: o pesquisador pode elaborar uma definição preliminar do problema a ser abordado pela pesquisa, com base em seus conhecimentos anteriores. A pesquisa à literatura auxiliará a clarificação da definição, bem como, a delimitação de um enfoque interessante para estudo, a partir do conhecimento que já se dispõe sobre o fenômeno. A atividade do pesquisador estará ora centrada na definição do fenômeno a ser pesquisado, ora no estudo de pesquisas já realizadas. Do mesmo modo a sua ação se estenderá às demais etapas da pesquisa, propiciando a definição dos objetivos e a configuração do arcabouço teórico em que a mesma estará inserida. 
A definição dos objetivos e a fundamentação teórica preparam a escolha da metodologia para coleta e análise dos dados. Nas diversas etapas é comum que o pesquisador necessite desenvolver procedimentos e instrumentos de análise que o auxiliem a avançar em seu trabalho. Os instrumentos de análise podem ser procedimentos específicos para coleta e análise dos dados ou instrumentos para a análise conceitual dos fenômenos que embasam a pesquisa, e acerca dos quais busca-se maior conhecimento.

Um instrumento utilizado em ciência para a análise conceitual dos fenômenos é o modelo.

O modelo constitui-se basicamente em uma "estrutura analítica que visa representar uma versão simplificada e abstrata da realidade" (Dicionário de Ciências Sociais, 1986, p. 773). Através dele busca-se estudar as relações entre uma série de variáveis. Em geral é composto por um conjunto de hipóteses a partir das quais são retiradas implicações ou previsões. Embora as hipóteses adotadas devam ter alguma relação com o tipo de situação a qual o modelo se aplica, elas não precisam constituir réplicas exatas do mundo real. O importante é que o modelo tenha boa capacidade de previsão.

Pode-se depreender, por esta definição, que o modelo responde a uma função explicativa porque "estabelece as noções, os objetos e as operações formais que permitirão, num dado momento, a testagem empírica de seus componentes." (Dicionário Geral das Ciências Humanas, p.300).

Neste artigo explicaremos a origem, construção e utilização de um modelo elaborado para auxiliar a análise do fenômeno "formação profissional", objeto de estudo de uma pesquisa conduzida pelas autoras.

\section{Histórico do Desenvolvimento da Pesquisa}

O objetivo da pesquisa era o de proceder a levantamento bibliográfico de artigos publicados sobre o tema "formação do psicólogo", visando identificar aspectos da formação que estavam sendo analisados pelos autores, os problemas por eles levantados e propostas sugeridas para a melhoria da formação.
Iniciou-se o levantamento dos artigos através de consulta aos exemplares de coleções de periódicos nacionais existentes nas bibliotecas do Instituto de Psicologia da Universidade de São Paulo e da Universidade Federal de São Carlos. Os periódicos deviam preencher os critérios de: periodicidade de publicação de pelo menos dez anos e possuir Conselho Editorial. A busca foi feita em todos os exemplares encontrados, desde o início de sua publicação até o ano de 1996.

Para seleção dos artigos relevantes ao tema da pesquisa foram utilizadas as palavras-chave "formação do psicólogo", atuação do psicólogo" e "profissão de psicólogo".

Entendeu-se nesta pesquisa como "formação" ao período abrangido pela graduação em Psicologia. Segundo Benko (1964/65, p.76) a formação "designa uma preparação pela qual o indivíduo adquire o domínio dos princípios fundamentais, das técnicas específicas e das atitudes adequadas para poder reagir corretamente nas situações iguais às anteriormente experimentadas, e resolver satisfatoriamente as tarefas novas que se apresentam em seu campo de trabalho".

A análise sistemática dos artigos encontrados foi iniciada pelos periódicos de longa duração, tais como, Arquivos Brasileiro de Psicologia, Boletim de Psicologia e Psicologia: Ciência e Profissão.

\section{Procedimentos Adotados para a Análise dos Dados}

Os artigos localizados através das palavras chave eram lidos e verificava-se se o seu conteúdo abordava como tema central a formação do psicólogo. Os artigos que abordavam a formação como tema secundário não passavam para a segunda etapa de análise .

Os artigos selecionados eram lidos novamente procedendo-se agora à análise temática de seus conteúdos (Severino, 1993). Para orientar esta análise, em termos de sistemática semelhante, foram elaborados roteiros de questões a serem seguidos pelas pesquisadoras. Dada a diferenciação de estrutura dos artigos de natureza teórica e daqueles que apresentavam relatos de 
pesquisa ou de experiência, foram elaborados roteiros específicos para a análise de cada tipo de artigo (Pardo, Piccirilli e Mangieri, 1993). Ao final de cada roteiro foram formuladas questōes que permitiam a comparação das informações obtidas em cada tipo de artigo visando, posteriormente, uma síntese final sobre as mesmas.

No decorrer da aplicação dos roteiros de questões surgiram alguns problemas, tais como, nem todos os artigos ofereciam respostas a todas as questões do roteiro, apesar do esforço de análise. Por exemplo: quanto aos relatos de pesquisa ou de experiência, em alguns deles não ficava claro qual era a questão de estudo abordada; havia muita diversidade quanto a metodologia utilizada para a coleta e apresentação dos dados, o que dificultava, não apenas a análise, mas também a comparação das produções apresentadas nos artigos; para vários dos artigos era difícil identificar sua contribuição para o tema "formação do psicólogo". Quanto aos artigos teóricos: muitas vezes era difícil identificar o tema central do artigo, bem como, os problemas levantados em relação ao mesmo; era comum o artigo levantar vários tipos de problemas, sem referenciá-los a temas específicos, ou então, ligando-os a temas bem amplos como "curso de Psicologia" ou "formação do psicólogo".

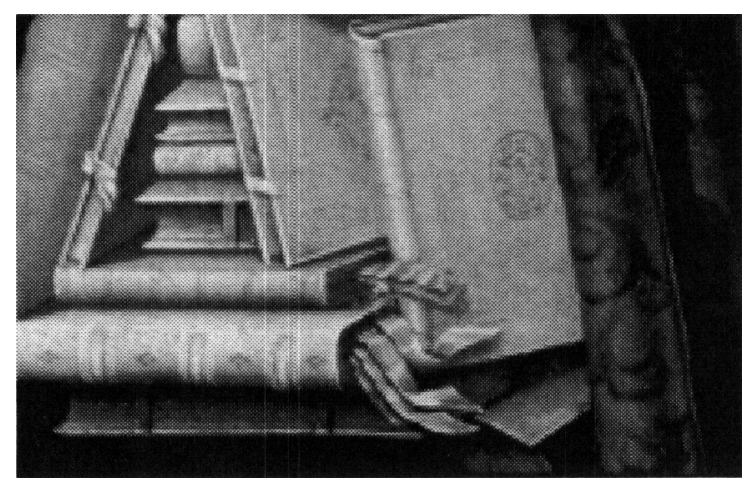

Toda esta diversidade encontrada no tratamento do tema "formação do psicólogo" dificultava sobremaneira tanto a classificação quanto a comparação das informações retiradas dos artigos. Os temas contidos nas questōes do roteiro deveriam facilitar a produção de categorias que servissem como pontos de apoio para a compreensão da estruturação e funcionamento do fenômeno "formação do psicólogo". E como se dirigiam apenas para a estrutura conceitual dos artigos não conseguiam superar as próprias lacunas de análise contidas nos mesmos.

Procurando contornar tais dificuldades, as pesquisadoras voltaram a estudar o fenômeno objeto da pesquisa, a "formação profissional". Neste estudo abordaram também o fenômeno "profissão", que está estreitamente ligado a questão da formação. A partir destes estudos, Pardo (1992) desenvolveu modelos de análise para a profissão e para a formação profissional. A seguir será apresentada uma sistematização das informaçōes obtidas nesta etapa do trabalho.

\section{A Profissão e a Formação Profissional}

Segundo Mello (1983) a profissão surge a partir de necessidades sociais para as quais se busque solução. Na tentativa de resolver problemas os homens sistematizam procedimentos e produzem intervenções nos eventos que pretendem alterar, visando a obtenção de estados ou de resultados mais satisfatórios. A seqüência de intervençōes e de alterações cria, ao longo do tempo, uma tradição na prestação de serviços, gerando um clima favorável para a aceitação social da profissão. É neste momento que, em geral, ocorre a regulamentação de uma profissão.

Por esta análise pode-se depreender que a profissão é um fenômeno composto de outros fenômenos, tal como se segue:

O Objeto de Estudo que constitui-se no conjunto de fenômenos em relação aos quais os profissionais são solicitados a interferir. Por exemplo: no caso do psicólogo o Objeto de Estudo é composto pelos fenômenos psicológicos, tais como, o desenvolvimento humano, o processo de aprendizagem e seus desvios, etc..

Os Procedimentos e Técnicas que constituem-se em ações especializadas desempenhadas pelos profissionais no decorrer da intervenção. O caráter 
especializado advém do fato de que os profissionais buscam manter um certo controle sobre os resultados a serem obtidos. No caso do psicólogo, o uso de técnicas de observação, a aplicação de testes, o uso de entrevistas, são exemplos de procedimentos e técnicas utilizados.

À medida em que cresce a tradição na prestação de serviços é elaborada a Legislação que vem regulamentar o exercício da profissão. A Legislação define funções, áreas de atuação profissional, apresentando limites dentro dos quais os profissionais podem atuar. Em geral, a elaboração de leis que regulamentam a formação profissional ocorre simultaneamente à regulamentação da profissão.

O Código de Ética surge a partir da iniciativa dos próprios profissionais que o elaboram, visando o estabelecimento de parâmetros para a avaliação da atuação profissional e também para o julgamento dos serviços prestados.

A análise apresentada anteriormente, que busca identificar fenômenos básicos componentes de um fenômeno mais complexo, bem como algumas de suas ligações, é o que estamos chamando de modelo de análise. Neste contexto o modelo de análise para o fenômeno Profissão pode ser representado pelo esquema apresentado no quadro 1.

Quadro 1 - Modelo de Análise para a Profissão
A representação indica que a Profissão é composta por outros fenômenos que têm significado próprio e mantêm inter-relações , à medida em que se referenciam no fenômeno mais amplo. A partir deste modelo podemos analisar partes do fenômeno Profissão, representadas pelos fenômenos que a compõem e também por suas interligaçōes, sem perdermos o elo de ligação com o fenômeno principal.

A partir do fenômeno Profissão foi desenvolvida a análise da Formação Profissional. A formação é composta por fenômenos semelhantes àqueles que compõem a profissão e, também, por outros fenômenos específicos deste processo. Passaremos a sua descrição.

A Legislação representa as leis que regulamentam a formação profissional. Ela define parâmetros para o funcionamento dos cursos de formação, tais como, carga horária, conteúdos do currículo mínimo, tempo mínimo e máximo para a formação, etc. Deve existir compatibilidade entre as diretrizes que orientam a formação e as que regulam o exercício profissional. O curso de formação sofrerá influência das funçōes e das áreas de atuação definidas na Legislação regulamentadora da profissão.

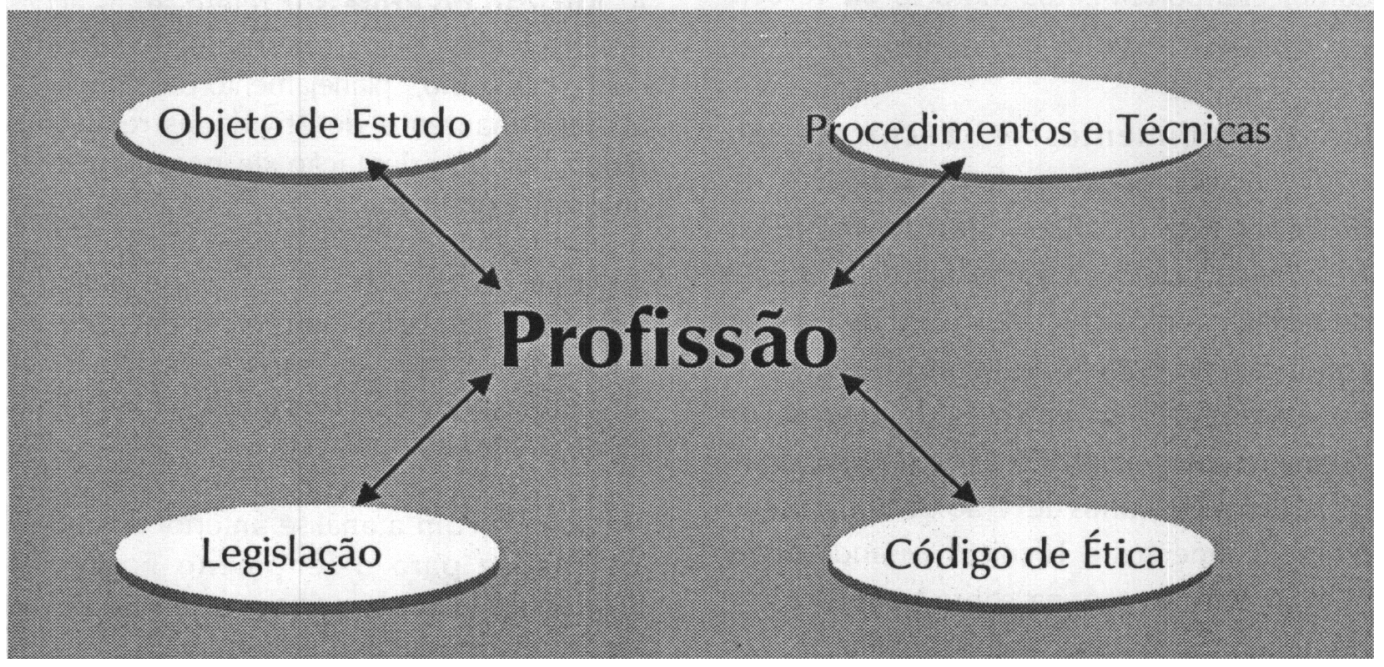


Os Conteúdos da Formação representam aqueles aspectos em torno dos quais deve desenvolver-se a aprendizagem dos alunos. São eles: o Objeto de Estudo, Procedimentos e Técnicas e Ética.

O Objeto de Estudo é representado pelo conhecimento sistematizado já existente sobre os fenômenos psicológicos, tal como, teorias, formulações iniciais sobre o funcionamento de certos fenômenos ou de seus aspectos. Também fazem parte do

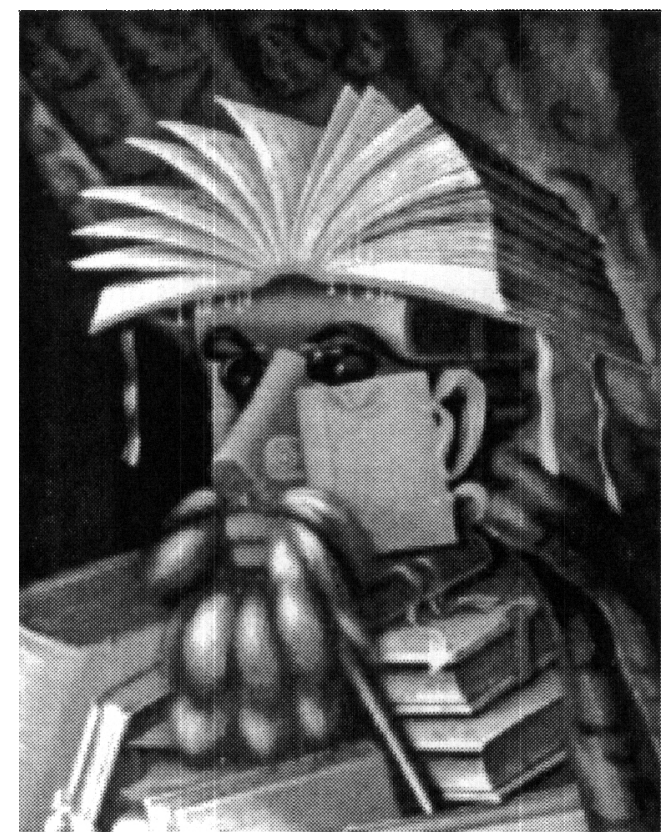

Objeto de Estudo os fenômenos com os quais o aluno tem contato através da prática, tais como, comportamentos motores ou verbais das pessoas e eventos ambientais.

Os Procedimentos e Técnicas são representados pelos modos sistemáticos de proceder que os alunos devem aprender. Neles estão incluídos a sistemática de aplicação de testes psicológicos, os procedimentos de condução de entrevistas, o uso de técnicas de observação e registros de dados, os procedimentos de análise e de interpretação dos dados. Os alunos deverão trabalhar sobre os Procedimentos e Técnicas visando obter fundamentação teórica sobre os mesmos e domínio quanto a sua aplicação.
A Ética representa um conjunto de valores que deve permear todas as açōes dos participantes do processo de formação. Fundada no respeito a pessoa humana, a Ética deve conduzir professores e alunos a analisarem suas açōes, tendo em vista o aperfeiçoamento da própria formação e a melhoria dos serviços prestados à população, pelo curso de Psicologia. Neste sentido a Ética não deve ser apenas um conteúdo tratado num determinado momento do curso, mas sim uma prática cotidiana.

Até este ponto nossa análise procedeu à transposição dos fenômenos que compõem a profissão para o contexto da formação profissional. Trataremos agora de fenômenos específicos que também compõem a formaçāo. Eles estão englobados na Dinâmica do Processo e representam fatores e atuações que colocam em funcionamento o curso de formação. São eles: Administração, Atuação do Professor e Atuação do Aluno.

A Administração compreende as ações e decisões que definem, regulam e orientam o funcionamento do curso de Psicologia no seu todo e nos seus diversos setores, tais como, laboratórios, Setor de Psicologia Aplicada, etc. Quanto ao funcionamento do curso como um todo algumas decisões importantes referem-se a definição de horários de funcionamento, da carga horária de disciplinas e estágios relacionados às diferentes áreas de atuação do psicólogo, de conteúdos a serem ministrados nas diversas disciplinas, etc. Há também decisões e atuações que ocorrem nos Setores do Curso, tais como, na Clínica Psicológica, no Setor de Psicologia Escolar, etc.

A Atuação do Professor refere-se às ações desenvolvidas pelo professor no decorrer do curso, tais como, planejamento de disciplinas, acompanhamento de atividades realizadas pelos alunos, orientação de pesquisas e de atividades práticas.

A Atuação do Aluno refere-se a ações desenvolvidas pelo mesmo no decorrer do curso, tais como, estudos e execução de atividades práticas, elaboração de trabalhos, atendimento a população.

De acordo com a análise anterior o modelo de análise para o fenômeno Formação Profissional pode ser representado pelo esquema apresentado no quadro 2. 


\section{Quadro 2 - Modelo de Análise para a Formação Profissional}

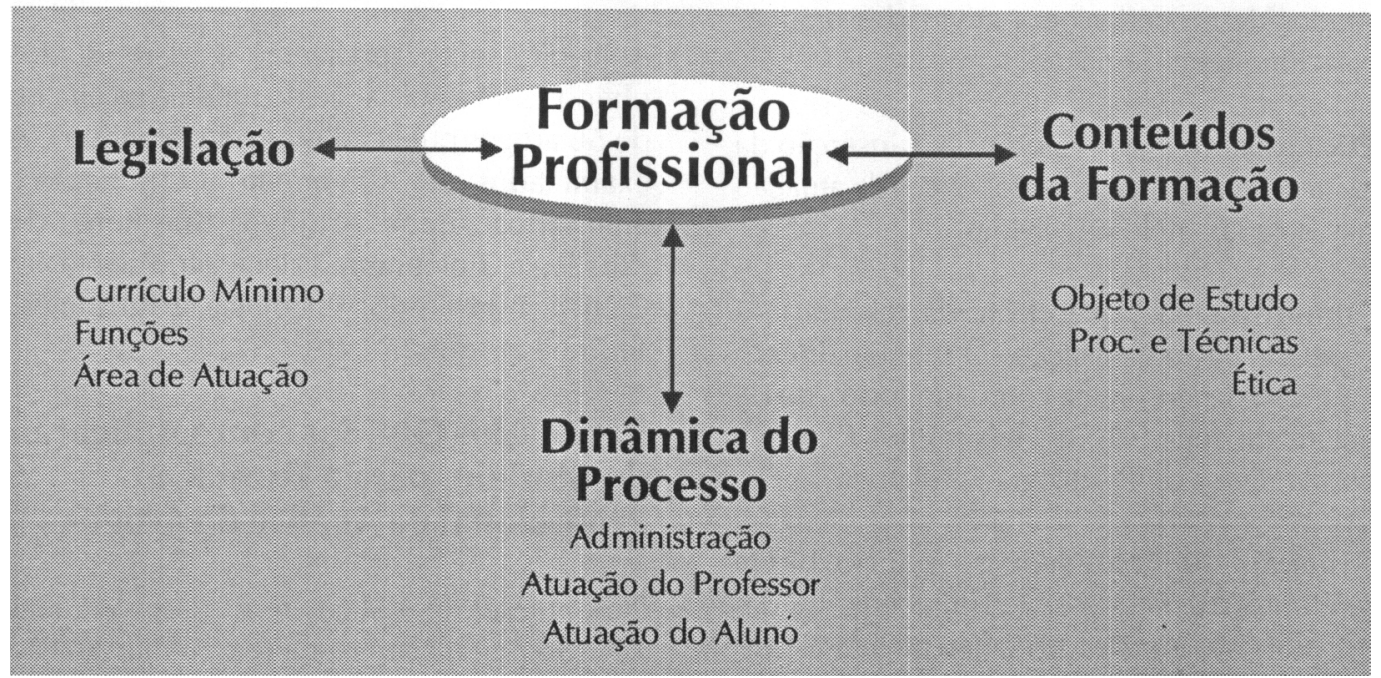

Neste ponto do trabalho as pesquisadoras haviam chegado a uma concepção sobre a Formação Profissional, que lhes permitia proceder a sua decomposição em outros fenômenos, assumindo que tais fenômenos eram representativos da estrutura da mesma. Portanto, o modelo de análise para a Formação Profissional constitui-se numa hipótese de trabalho.

\section{Utilização do Modelo de Análise para a Formação Profissional como Instrumento de Trabalho na Pesquisa}

Como relatado anteriormente as pesquisadoras estavam encontrando dificuldade na classificação das informações provenientes dos artigos, quando utilizavam os roteiros de questões para obtenção da mesma. A partir do estudo dos fenômenos Profissão e Formação Profissional, e elaboração dos modelos de análise, estes passaram a ser utilizados para selecionar $\mathrm{e}$ categorizar as informações relevantes.

Tomando como base o modelo da Formação Profissional as pesquisadoras procuravam identificar quando uma dada informação se referia a algum dos fenômenos previstos no mesmo. Procurava-se também distinguir se a informação referia-se a uma afirmação sobre o que a formação tem, ou sobre o que a formação deveria ter. Deste modo cada informação era classificada quanto ao aspecto da formação ao qual se referia e quanto ao tipo de afirmação que apresentava sobre a mesma.

Considerou-se como unidade cada vez que era encontrada uma dada informação, ao longo do texto. Assim, contava-se nova ocorrência se uma informação referente ao mesmo conteúdo fosse encontrada em trechos diferentes do artigo.

A seguir são apresentados os critérios utilizados para classificação das informações em cada aspecto previsto pelo modelo.

Legislação: quando o texto se referia ao conteúdo das leis ou a interpretações apresentadas pelos autores quanto ao conteúdo das mesmas.

Objeto de Estudo: quando o texto se referia a teorias tratadas no curso ou ao conhecimento do fenômeno psicológico desenvolvido a partir do estudo e/ou da prática. 
Procedimentos e Técnicas :quando o texto se referia a técnicas ou a suas definições, a modos de proceder ou a atividades práticas relacionadas a formação.

Ética :quando havia referência a inserção da ética no curso, ou a aspectos éticos da atuação das pessoas nele envolvidas.

Administração : quando havia referência a aspectos da organização ou funcionamento do curso de Psicologia como um todo, ou de algum de seus Setores, tais como, Clínica Escola, Setor de Psicologia Escolar, etc.

Atuação do Professor : quando havia referência a ações desenvolvidas ou atribuídas ao professor no decorrer das atividades do curso.

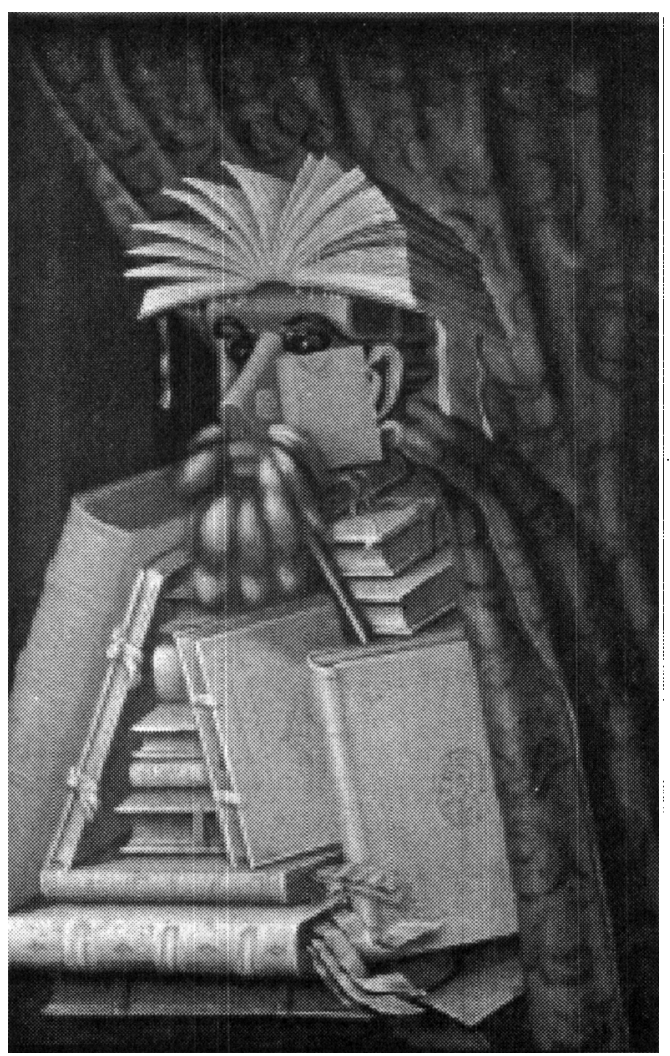

Atuação do Aluno : quando havia referência a ações desenvolvidas ou atribuídas ao aluno no decorrer das atividades do curso.

As pesquisadoras procederam à classificação independentemente das informaçōes em dez por cento dos artigos analisados e encontraram um indice de $75 \%$ de concordância.

A seguir serão apresentados os resultados obtidos com a aplicação do modelo na análise de 56 artigos publicados em cinco periódicos examinados até o momento. Os periódicos analisados foram: Arquivos Brasileiros de Psicologia, Boletim de Psicologia, Psicologia: Ciência e Profissāo, Psicologia e Psicologia: Teoria e Pesquisa.

\section{Resultados Obtidos com a Aplicação do Modelo para a Formação Profissional na Análise de Artigos}

De um total de 404 referências encontradas $147(36,3 \%)$ diziam respeito a Administração (Curso como um Todo). Esta freqüência superou a do total de indicações relacionadas aos Conteúdos da Formação (110 ou $27 \%$ das referências encontradas). Este resultado indica que os autores estavam se referindo com maior freqüência a aspectos estruturais do funcionamento do curso de Psicologia, tais como, currículo, carga horária de disciplinas, questões da estrutura universitária, ênfase a ser dada na formação. Pode-se também supor que tal freqüência indica a importância que estava sendo atribuída a decisões e ações de caráter administrativo para o funcionamento e para alteraçóes no funcionamento do curso.

Por outro lado a Atuação do Professor, Atuação do Aluno e Administração (Setor) foram relativamente pouco analisados, quando comparados com o aspecto mais analisado dentro da Dinâmica do Processo (Administração : Curso como um Todo). Estes aspectos tiveram respectivamente $10,8 \%$, $8,9 \%$ e $6,9 \%$ de referências.

A respeito dos Conteúdos da Formação observou-se um desequilíbrio na freqüência de referências à Ética $(2,4 \%)$ em relação aos dois outros aspectos - Procedimentos $\mathrm{e}$ Técnicas (12,8\%) e Objeto de Estudo $(11,8 \%)$ - sendo aquela bem menos referida. Este fato indica que, apesar de alguns autores reclamarem quanto ao isolamento da Ética dentro do Curso, a maioria deles não apresentou um tratamento integrado da mesma com os demais aspectos da formação de que tratam em seus artigos. 


\section{Considerações finais}

Os resultados obtidos mostram que o modelo para a análise da formação profissional cumpriu sua função quanto a previsão de aspectos que compõem a formação do psicólogo. Nos artigos analisados todas as informações relevantes puderam ser incluídas em algum dos aspectos da formação previstos pelo modelo.

É possível que tal modelo possa ser útil na sistematização de outros tipos de dados relacionados a formação, tais como, aqueles provenientes de entrevistas com profissionais que trabalham no curso de Psicologia, ou dados da observação direta do funcionamento do curso em seus diversos aspectos. A utilização do modelo para orientar a análise de dados provenientes de outras fontes servirá para continuar testando a utilidade do mesmo ou propondo seu aperfeiçoamento.
Sendo a formação profissional um fenômeno complexo é interessante que se procure estudá-lo decompondo-o em outros fenômenos com os quais mantenha relação. Deste modo é possível proceder a análise de suas partes sem perder de vista o todo. $O$ modelo de análise aqui apresentado possibilitou este tipo de enfoque no estudo do fenômeno formação do psicólogo.

Em outros artigos as autoras estarão expondo com maior detalhe os conteúdos encontrados para cada aspecto da formação previsto no modelo de análise, e comparando os problemas e propostas para a formação do psicólogo encontrados nos artigos analisados.
Benko, A. Formação profissional do psicólogo. Boletim de Psicologia, São Paulo, v. 16/17, n. 47 a 50, p. 75-89, 1964/65.

Dicionário das Ciências Sociais. (1986) Rio de Janeiro: Fundaçāo Cetúlio Vargas, . p. 773.

Dicionário Geral das Ciências Humanas. (1984) Lisboa: Ediçōes Setenta, p.300.

Severino, A. J. Metodologia do trabalho cientifico. ( 1993 ) $19^{\mathrm{a}}$ ed. São Paulo: Cortez/Autores Associados.
Mello, S.L. Psicologia e Profissão em Săo Paulo. 1’ ed., 5a impressão.(1983) São Paulo: Ática.

pardo, M.B.L. Que profissional queremos formar?(1992) São Carlos: Universidade Federal de Sāo Carlos, Texto digitado.

Pardo, M.B.L., Piccirilli, I., Mangieri, R.H.C. Uma proposta de metodologia para a análise de artigos sobre o tema "formação do psicólogo". In: 45a Reunião Anual da Sociedade Brasileira para o Progresso da Ciência, (1993). Recife, Anais da 45á Reuniäo Anual. São Paulo p.937. 